DOI: $10.17805 /$ zpu.2018.1.23

\title{
Религиозно-философское наследие Чже Цонкапы в духовной культуре ойратов
}

\author{
Ю. Ю. ЭРЕНДЖЕНОВА
}

\author{
КАЛМЫЦКИЙ ГОСУДАРСТВЕННЫЙ УНИВЕРСИТЕТ ИМЕНИ Б. Б. ГОРОДОВИКОВА
}

В настоящее время в связи с возрождением и развитием буддизма в Калмыкии встает вопрос о происхождении и преемственности буддийской традиции калмыков. Буддийская философия и религиозный культ имели структурирующее значение и влияли на мировоззрение и образ жизни предков калмыков - ойратов. При этом главенствующее место занимала тибетская традиция гелуг, основанная Чже Цонкапой на рубеже XIV-XV вв. Глубинные философские трактаты и сеть монастырей со строгой системой образования составили обширное религиозно-философское наследие Цонкапы. В статье рассматриваются доктринальные основания тибетской буддийской традиции гелуг и их интеграция в духовное пространство ойратов в контексте межкультурного взаимодействия Тибета и ойратских ханств.

B XVII в. в результате вмешательства ойратов традиция гелуг заняла доминирующее положение в Тибете, а буддизм стал национально-государственной религией самих ойратов. Это способствовало консолидации ойратского социума и формированию их культурного пространства на основе буддийской картины мира. Ойратские монахи обучались в гелугпинских монастырях, переводили и распространяли в родных кочевьях философские трактаты Цонкапы, которые, составив теоретическую базу традиции гелуг, разъясняли суть поэтапного совершенствования личности на пути к просветлению и определяли сущностное содержание тантрической ритуальной практики.

На основе данных научных исследований, основополагающих сочинений Чже Цонкапы, исторических хроник, образцов ойратского законодательного и народного творчества автор статьи приходит к выводу, что базовые категории философской традиции гелуг получили отражение в мировоззрении ойратов и способствовали последующему формированию их культуры. В соответствии с учением Цонкапы о совершенствовании личности через практику отречения, сострадания и мудрости ойраты важными считали такие качества, как воздержанность, гуманность, добродетель, справедливость. Буддийская мудрость, которая заключается в осознании взаимообусловленности бытия посредством дискурсивного анализа, согласовывалась с категориями коллективной ответственности, взаимосвязанности, осознанного стремления к обучению и самосовершенствованию, являвшимися духовными регуляторами жизни ойратского общества. Наряду с философским осмыслением учения Цонкапы, которое в основном было доступно духовной и светской элите, большое распространение получила и обрядовая практика.

Ключевые слова: тибетский буддизм; Цонкапа; гелуг; буддийское учение; традиция ламрим; духовная культура; ойраты; калмыки; Калмыкия

\section{ВВЕАЕНИЕ}

Иичость тибетского религиозного деятеля, философа, просветителя Чже Цон1 капы (1357-1419) и его творчество подробно исследованы учеными на основе агиографической литературы и его философских трудов. Исследователями (Багаева, 2007; Thurman, 2009; Аонец, 2016) проводится анализ текстов Цонкапы и основанных на них воззрений школы гелуг — традиции буддийского монастырского образования и ритуальной практики.

B XVII в. последователи гелуг получили военную поддержку ойратского Гушихана (1582-1654), что способствовало утверждению доминирующего положения их традиции в Тибете и возвышению института далай-лам (Санчиров, 1977; Шакабпа, 2003; Китинов, 2004). В свою очередь глава Тибета стал духовным наставником ойратских правителей и вручал им ханскую печать. Это позволило наиболее влия- 
тельным ойратам объединить разрозненные этнические группы и укрепить мощь Ажунгарского, Хошутского и Калмыцкого ханств, сыгравших значительную роль в политике и экономике Центрально-Азиатского региона и южных рубежей России в XVII-XVIII вв.

В 1640 г. ойраты официально отказались от практики шаманизма и признали буддизм национальной религией, закрепив это в «Великом уложении» (ойр. «Ик Цааз»). С этого времени отмечается влияние буддизма на религиозное сознание ойратов (Бичеев, 2006), что существенным образом отразилось и на их культуре (Калмыки, 2010; Бадмаев, Манджиев, Уланов, 2012).

Целью данной статьи является анализ интеграции доктринальных оснований учения Цонкапы в духовное пространство ойратов через активную деятельность последователей традиции гелуг. Аля определения степени влияния созданной Цонкапой религиозно-философской базы на ойратов необходимо выделить основополагающие концепции его учения, раскрыть буддийский компонент в ментальности ойратов и определить те формы их культуры, в которых отражается наследие Цонкапы.

\section{СУЩНОСТЬ УЧЕНИЯ ЦОНКАПЫ}

Согласно жизнеописанию Цонкапы, он долгое время обучался у мастеров всех школ тибетского буддизма (rGyal-dbang chos-rje, 2000). Такое всестороннее изучение буддийской теории и практики позволило Цонкапе синтезировать эти познания для формирования новой традиции гелуг, что дословно означает «традиция добродетели» (Tu'u-bkvan ..., 1984: 235-236). В основе ее мировоззренческих установок лежит философия пустотности индийской школы Мадхъямака-прасангика, базисной же ценностью является безусловная монашеская дисциплина, служащая залогом постижения и практики аутентичного буддийского учения (Багаева, 2007: 12-13). При этом важнейшее значение имеет система обетования, которая способствует повышению уровня осмысленности и самоконтроля (Аонец, 2016: 151-152). Наряду с нравственностью Цонкапа возводит в абсолют личность ламь (тиб. духовного учителя) и указывает на важность вверения ученика «благому другу», подразумевая под этим глубокую веру в духовного наставника (Цонкапа, 2007: 60). Такое трепетное отношение к ламе признавалось основой всех достоинств на пути к совершенствованию личности (rJe tsong-khapa ..., 2001b).

Особое значение имеют философские труды Цонкапы по системе ламрим, в которых раскрываются принципиальные положения сутры и тантры. Основу этого подхода заложили индийские пандиты Нагарджуна (II-III вв.) и Асанга (IV в.), которые написали многочисленные трактаты по буддийской философии и систематизировали их для продуктивной учебы и практики (H. H. the Dalai Lama, 2003: 28). Позднее буддийский мыслитель Атиша (XI в.), руководствуясь их работами, составил труд «Светоч на пути к пробуждению», ставший, по сути, первым изложением буддийской философии по принципу типологизации уровней личности на этапах пути к просветлению. Взяв воззрения индийских пандит за теоретико-методологическую основу, Цонкапа совершил переход на качественно новый уровень познания буддийской теории в своих трактатах «Аамрим ченмо» («Большое руководство к этапам пути пробуждения») и «Нагрим ченмо» («Большое руководство к этапам пути мантры»). Уникальность же этих фундаментальных трудов состоит в том, 
что Цонкапа «взялся за объяснение самых трудных для понимания фрагментов из индийских текстов» (Аалай-лама, 2016: 278).

Через систему поэтапного совершенствования личности и критический анализ последователи гелуг познают природу человеческой сущности и способы достижения трансцендентального состояния освобождения. Тремя основами для такого духовного поиска признаются отречение от сансарического бытия, бодхичитта (санскр. - устремление к просветлению), выражающаяся в любви и сострадании ко всем живым существам, и мудрость, заключающаяся в осознании взаимообусловленности феноменов и вытекающей из этого пустотности самобытия (rJe tsongkhapa ..., 2001a).

После изучения философской базы Цонкапа считает важным практику тантры, которая включает в себя обширный культ и систему психосоматических регуляций сознания посредством применения деструктивных эмоций (гнев, вожделение, гордыня) для трансформации ума практикующего. В своем фундаментальном труде Цонкапа разъясняет этапы пути тантры, которые включают в себя визуализацию божества-идама, йогическое созерцание, рецитацию мантр, что реализуется на практике через сложную систему обрядов инициации и ежедневных ритуалов (Цонкапа, 2011). Сформировавшись в Индии, тантра способствовала расширению буддийского пантеона за счет включения в него различных божеств, чей внешний вид и атрибутика несли скрытый смысл и могли быть правильно восприняты лишь посвященными. В тибетском обществе наряду с духовной практикой тантра составила базис традиционной медицины, астрологии, а также целого комплекса ритуалов для удовлетворения личных и общественных нужд населения.

Таковы базовые категории учения Цонкапы, изложенные в его сочинениях, которые проповедовались последователями его традиции и были транслированы ойратам, когда те признали буддизм национальной религией.

\section{ИНТЕГРАЦИЯ ОСНОВНЫХ ИАЕЙ РЕАИГИОЗНО-ФИАОСОФСКОГО НАСАЕАИЯ ЦОНКАПЫ В АУХОВНУЮ КУАБТУРУ ОЙРАТОВ}

Сама традиция Цонкапы гелуг ассоциируется с желтыми шапками, которые монахи надевают во время религиозных ритуалов. Будучи отличительным признаком этой школы, желтый цвет (ойр. - шар) стал священным для всех монголоязычных народов, принявших буддизм, в том числе и для ойратов, а буддийское учение стало называться шар шажин. Поклонение традиции гелуг встречается в благопожеланиях и гимнах (Борджанова, 2007: 310-314). В эпосе «Ажангар» четыре благородные истины буддизма названы «желтыми» (Ажангар ..., 1977: 20), а песни ойратов, восхвалявшие буддийских монахов, назывались шар дун, что дословно означает «желтая песня» (Ван, 2012: 58-64).

Буддийская культура тибетской традиции гелуг нашла отражение в изобразительном и декоративно-прикладном искусстве (Калмыки, 2010: 481-485). Влияние гелуг прослеживается и в семантике личных имен ойратов, когда новорожденных нарекали тибетскими и санскритскими именами с буддийской смысловой нагрузкой (Монраев, 2012). В устном народном творчестве часто упоминается и сам Цонкапа под именем Зункъа-гегян, а у калмыков, потомков ойратов, сохранился обычай поклонения ему на праздник Зул (Калмыки, 2010: 294-297). Таким образом, как отмечает А. Б. Бичеев, стремительное распространение буддиз- 
ма произвело «культурное потрясение» традиционного сознания ойратов (Бичеев, 2006: 184).

Большое значение для ойратов имели монастыри, основанные Цонкапой и его последователями. Ойратские монахи проходили обучение преимущественно в стенах колледжа Гоманг монастыря Арепунг. Обучившись буддийской логике и эпистемологии, личностному развитию, философии срединности, метафизике, нравственным устоям, монахи возвращались в родные кочевья и создавали национальные монастыри.

Самым известным из ойратских выпускников Арепунг Гоманга считается Заяпандита (1599-1662). В 1648 г. он создал ойратскую письменность тодо бичиг ( «ясное письмо») и изложил на ней переводы основных буддийских текстов, в том числе и сочинения Цонкапы (Музраева, 2012: 58-64). Опираясь на эти труды, монахи проповедовали буддийское учение об эгоистической природе сансарических страданий и способах избавления от них. Эти знания влияли на миропонимание ойратов и изменяли их духовно-ценностные ориентиры. Осознание причинно-следственной связи всех феноменов, в буддизме называемой законом кармы, способствовало тому, что ойраты стали воспринимать свою жизнь как результат собственных прошлых благих и негативных деяний. Придерживаясь монашеской дисциплины традиции гелуг, ойратские монахи своим высоконравственным поведением создавали образ идеала праведного человека. Миряне приобретали религиозные заслуги посредством соблюдения кратковременных обетов, поклонения сакральным объектам, пожертвований в пользу монастырей, совершения паломничеств к буддийским святыням Тибета. Зая-пандита особое внимание уделял и тантре, переводя тантрические тексты, посвящая верующих в таинства практики и совершая необходимые обряды (Норбо, 1999). Также тантрические методы можно выделить в иконографии, медицине, астрологии, обрядах призывания дождя и других важных для мирского населения ритуальных действиях (Житецкий, 1893: 59-64).

Через призму религиозно-философского наследия Чже Цонкапы у ойратов сложилась буддийская картина мира. Три основы духовного пути нашли отражение в личностных качествах ойратов. Стремление к отречению способствовало развитию воздержанности во всех отношениях, а культивирование бодхичитты выражалось через гуманность и добродетель. Как отмечают современные калмыцкие ученые, этическое учение буддизма способствовало тому, что воинственные ранее кочевники при сохранении былого достоинства стали более мягкими, доброжелательными и терпимыми (Бадмаев, Манджиев, Уланов, 2012: 86). Ойраты стали больше ценить жизнь человека, называемую в буддизме драгоиенной. Например, в отличие от предыдущих законов монголоязычного мира создатели «Великого уложения» 1640 г. отказались от смертной казни за преступления против личности (в том числе убийство) и в качестве наказания предусматривали лишь отнятие материального имущества и скота. Казнили же только в случаях предательства и дезертирства с поля боя, поскольку это угрожало всеобщей безопасности и целостности ханства (Уланов, Бадмаев, Мацакова, 2016: Электронный ресурс). То есть для ойрата всеобщее благо было выше индивидуального, что в целом согласовывалось с буддийской мудростью о взаимозависимости бытия.

Следуя наставлениям Цонкапы, ойраты большое внимание уделяли процессу обучения как необходимой ступени к самореализации. К примеру, смысловая на- 
правленность ойратского поучения «Ключ разума» («Оюн тулкур»), где представлены назидательные изречения и поучительные афоризмы, сводится к противопоставлению образованности невежеству, а также важности осознанности и самоконтроля (Аунный свет ..., 2003: 233). В рамках домашнего образования обучались дети мирян, а в середине XVIII в. глава Калмыцкого ханства Аондук-Ааши ввел обязательное обучение для мальчиков всех сословий до пятнадцати лет (Сергеев В., Сергеев Б., 1998: 69-70). Несомненно, такой подход к образованию возможен был лишь при осознанном стремлении к обучению.

\section{ЗАКАЮЧЕНИЕ}

Таким образом, краткий анализ интеграции религиозно-философского наслеАия Цонкапы в духовную культуру ойратов показал, что созданные тибетским просветителем сочинения и проповедовавшая их школа гелуг оказали существенное влияние на сознание ойратов и последующее формирование их культурного пространства.

Религиозное мироощущение ойратов укреплялось через культовую деятельность буддийских монахов, которые мотивировали духовную практику мирян. Будучи необходимой ступенью на пути к просветлению с точки зрения Цонкапы, образование стало неотъемлемой частью культуры ойратского этноса. Буддизм воспринимался ими как комплексная система обучения и передачи основополагающих принципов нравственности в сотериологическом контексте с целью их практического применения в жизни. С принятием буддизма в качестве национальной религии воинственные ойраты стали гуманнее. Так, для ойратов постулаты буддизма, транслированные через последователей тибетской традиции гелуг, стали основой морали, нравственности и самосовершенствования.

\section{СПИСОК АИТЕРАТУРЫ}

Багаева, К. А. (2007) Мировоззренческие основы традиции гелугпа в Центральной Азии : автореф. дис. ... канд. филос. наук. Чита. 22 с.

Бадмаев, В. Н., Манджиев, Н. Ц., Уланов, М. С. (2012) Ауховная культура калмыцкого этноса (опыт философского исследования). Элиста : Издательство Калмыцкого университета. 156 с.

Бичеев, Б. А. (2006) Мифолого-религиозные основы формирования этнического сознания калмыков : дис. ... А-ра филос. наук. Ставрополь. 364 с.

Борджанова, Т. Г. (2007) Обрядовая поэзия калмыков (система жанров, поэтика). Элиста : Калм. кн. иза-во. 592 с.

Ван, Гао Чао (2012) Традиционная музыкальная культура ойратов. Элиста : АУ РК Издательский дом «Герел». 264 с.

Аалай-лама (2016) Путь к просветлению. Аекции о Чжэ Цонкапе. М. : Издательство «Э». 320 с.

Ажангар. Калмыцкий народный эпос (1977) / отв. ред. А. Ц. Бартунова. Элиста : Калм. кн. изА-во. 382 с.

Аонец, А. М. (2016) О роли системы обетования в развитии личности как субъекта освобождения в буддизме // Гуманитарный вектор. Т. 11. № 2. C. 147-153. DOI: 10.21209/2307-1826-2016$11-2-147-153$

Житецкий, И. А. (1893) Очерки быта астраханских калмыков. Этнографические наблюдения 1884-1886 гг. М. : Типография М. Г. Волчанинова. 74 с.

Китинов, Б. У. (2004) Священный Тибет и воинственная степь: буддизм у ойратов (XIII-XVII вв.). М. : Т-во научных изданий КМК. 191 с.

Калмыки (2010) / отв. ред. Э. П. Бакаева, Н. А. Жуковская. М. : Наука. 568 с. 
Аунный свет : Калмыцкие историко-литературные памятники (2003) / сост., ред. А. В. Бадмаев. Элиста : Калм. кн. изд-во. 477 с.

Монраев, М. У. (2012) Калмыцкие личные имена (семантика). Элиста : АУ РК Издательский Аом «Герел». 256 с.

Музраева, А. Н. (2012) Буддийские письменные источники на тибетском и ойратском языках в коллекциях Калмыкии. Элиста : ЗАОр «НПП "Ажангар"». 224 с.

Норбо, Ш. (1999) Зая-пандита. Элиста : Калм. кн. изд-во. 335 с.

Санчиров, В. П. (1977) Теократия в Тибете и роль Гуши-хана в ее окончательном утверждении // Аамаизм в Калмыкии / отв. ред. В. П. Аарбакова. Элиста : Калм. кн. изд. 111 с. С. 14-25.

Сергеев, В. С., Сергеев, Б. В. (1998) Уголовное и гражданское право калмыков XVII-XVIII веков (историко-правовые очерки). Элиста : «АПП "Ажангар"». 223 с.

Уланов, М. С., Бадмаев, В. Н., Мацакова, Н. П. (2016) Буддизм и правовая традиция в Монголии [Электронный ресурс] // Былые годы. Т. 42. Вып. 4. С. 1068-1076. URL: http://bg.sutr.ru/ pdf.html?n=1480333788.pdf (дата обращения: 09.12.2017).

Цонкапа, Чже (2007) Большое руководство к этапам пути пробуждения : в 2 т. СПб. : Изд. А. Терентьева. Т. 1.786 с.

Цонкапа, Чже (2011) Большое руководство к этапам пути мантры : в 2 т. СПб. : Изд. А. Терентьева. Т. 1.512 с.

Шакабпа, В. А. (2003) Тибет: политическая история. СПб. : ИзА-во «Нартанг». 428 с.

H. H. the Dalai Lama (2003) The Path to Enlightenment. Delhi : Motilal Banarsidass Publishers Pvt. Ltd. 238 p.

Thurman, R. A. F. (2009) Life and Teachings of Tsongkhapa. Dharamsala : Library of Tibetan Works \& Archives. 289 p.

rGyal-dbang chos-rje (2000) 'Jam-mgon chos-kyi rgyal-bo tsong-kha-ba chen-po'i rnam-thar. Sarnath-Varanasi : XXIX GSWC CIHTS. 650 р. (На тиб. яз.).

rJe tsongkhapa, blobzang gragspa (2001a) Lamgyi gtsobo rnampa gsumgyi rtsaba bzhugsso // Chosspyod rabgsal skalbzang skyebo'i mgulrgyan zhesbyaba zhugsso. Mundgod : Drepung Loseling Library Soceity. Pp. 344-347. (На тиб. яз.).

rJe tsongkhapa, blobzang gragspa (2001b) Yontan gzhirgyurma bzhugsso // Chosspyod rabgsal skalbzang skyebo'i mgulrgyan zhesbyaba zhugsso. Mundgod : Drepung Loseling Library Soceity. Pp. 7-10. (На тиб. яз.).

Tu'ubkvan, blobzang choskyi nyima (1984) Tu'ubkvan grubmtha'. Lanzhou : Kansu'u mirigs dpeskrunkhang. 487 р. (На тиб. яз.).

Aата поступления: 19.12.2017 2.

\section{JE TSONGKHAPA'S RELIGIOUS AND PHILOSOPHICAL HERITAGE \\ IN THE OIRAT SPIRITUAL CULTURE \\ YU. YU. ERENDZHENOVA}

KaLMYK STATE UNIVERSITY NAMED AFTER B. B. GORODOVIKOV

At present, due to the revival and development of Buddhism in Kalmykia, there arises the question of the origin and continuity of the Kalmyks' Buddhist tradition. Buddhist philosophy and religious cult had structuring significance and influenced the mentality and way of life of the Kalmyks' ancestors the Oirats. Herewith, the predominant place was occupied by the Tibetan Gelug tradition, founded by Je Tsongkhapa at the turn of the 15 th century. Profound philosophical treatises and a network of monasteries with a strict education system formed the extensive religious and philosophical heritage of Tsongkhapa. The article deals with the doctrinal foundations of the Buddhist Gelug tradition, their integration into the spiritual space of the Oirats in the context of the intercultural interaction of Tibet and the Oirat Khanates.

In the 17 th century, as a result of the Oirats' intervention, the Gelug tradition took a dominant position in Tibet, and Buddhism became a national-state religion of the Oirats themselves. That con- 
tributed to the consolidation of the Oirat society and the formation of their cultural space based on the Buddhist picture of the world. Oirat monks studied in the Gelug monasteries, translated Tsongkhapa's philosophical treatises and distributed them across their nomad territories; the treatises explained the essence of the gradual improvement of the personality on the path to enlightenment, determined the essential content of Tantric ritual practice, and constituted the theoretical basis of the Gelug tradition.

Based on the data of scientific research, core writings of Tsongkhapa, historic chronicles, samples of Oirat legislative and folk art, the author of the article concludes that the basic categories of the Gelug philosophical tradition were reflected in the Oirats' worldview and contributed to the subsequent formation of their culture. In accordance with Tsongkhapa's teaching on personal perfection through the practice of renunciation, compassion and wisdom, the Oirats attached great importance to such qualities as chastity, humanity, virtue, and justice. Buddhist wisdom, consisting in the awareness of the interdependence of existence through discursive analysis, cohered with the categories of collective responsibility, interconnectedness, a conscious aspiration to learning, and self-perfection that were the spiritual regulators of the life of the Oirat society. Along with the philosophical interpretation of Tsongkhapa's teachings, which was mainly accessible to the spiritual and secular elite, ritual practice was also widely spread.

Keywords: Tibetan Buddhism; Tsongkhapa; Gelug; Buddhist teaching; lamrim tradition; spiritual culture; Oirats; Kalmyks; Kalmykia

\section{REFERENCES}

Bagaeva, K. A. (2007) Mirovozzrencheskie osnovy traditsii gelugpa $v$ Tsentral'noi Azii: Thesis of Dis. ... Candidate of Philosophy. Chita. 22 p. (In Russ).

Badmaev, V. N., Mandzhiev, N. Ts. and Ulanov, M. S. (2012) Dukbovnaia kul'tura kalmytskogo etnosa (opyt filosofskogo issledovaniia). Elista, Kalmyk State University Press. 156 p. (In Russ.).

Bicheev, B. A. (2006) Mifologo-religioznye osnovy formirovaniia etnicheskogo soznaniia kalmykov : Dis. ... Doctor of Philosophy. Stavropol'. 364 p. (In Russ.).

Bordzhanova, T. G. (2007) Obriadovaia poeziia kalmykov (sistema zhanrov, poetika). Elista, Kalmyk Publ. House. 592 p. (In Russ.).

Van, Gao Chao (2012) Traditsionnaia muzykal' naia kul'tura oiratov. Elista, "Gerel" Publ. House. 264 p. (In Russ.).

Dalai-lama (2016) Put' k prosvetleniiu. Lektsii o Je Tsonkape. Moscow, "E" Publ. 320 p. (In Russ.). $382 \mathrm{p}$.

Jangar. Kalmytskii narodnyi epos (1977) / ed. by A. Ts. Bartunova. Elista, Kalmyk Publ. House.

Donets, A. M. (2016) O roli sistemy obetovaniia v razvitii lichnosti kak sub'ekta osvobozhdeniia v buddizme. Gumanitarnyi vector, vol. 11, no 2, pp. 147-153. (In Russ.).

Zhitetskii, I. A. (1893) Ocherki byta astrakbanskikb kalmykov. Etnograficheskie nabliudeniia 1884-1886 gg. Moscow, M. G. Volchaninov Publ. 74 p. (In Russ.).

Kitinov, B. U. (2004) Sviasbchennyi Tibet i voinstvennaia step': buddizm u oiratov (XIII-XVII vv.). Moscow, "KMK" Partnership of Scientific Publ. 191 p. (In Russ.)

Kalmyki [Kalmyks] (2010) / ed. by E. P. Bakaeva and N. L. Zhukovskaya. Moscow, Nauka Publ. 568 p. (In Russ.).

Lunnyi svet: Kalmytskie istoriko-literaturnye pamiatniki (2003) / ed. by A. V. Badmaev. Elista, Kalmyk Publ. House. 477 p. (In Russ.).

Monraev, M. U. (2012) Kalmytskie lichnye imena (semantika). Elista, "Gerel" Publ. House. 256 p. (In Russ.).

Muzraeva, D. N. (2012) Buddiiskie pis'mennye istocbniki na tibetskom i oiratskom iazykakb $v$ kollektsiiakb Kalmykii. Elista, "Dzhangar" Publ. House. 224 p. (In Russ.).

Norbo, Sh. (1999) Zaia-pandita. Elista, Kalmyk Publ. House. 335 p. (In Russ.).

Sanchirov, V. P. (1977) Teokratiia v Tibete i rol' Gushi-khana v ee okonchatel'nom utverzhdenii. In: Lamaizm v Kalmykii / ed. by V. P. Darbakova. Elista, Kalmyk Publ. House. 111 p. Pp. 14-25. (In Russ.). 
Sergeev, V. S., Sergeev, B. V. (1998) Ugolovnoe i grazhdanskoe pravo kalmykov XVII-XVIII vekov (istoriko-pravovye ocherki). Elista, "Dzhangar" Publ. 223 p. (In Russ.).

Ulanov, M. S., Badmaev, V. N. and Matsakova, N. P. (2016) Buddizm i pravovaia traditsiia v Mongolii. Bylye gody, vol. 42, no 4, pp. 1068-1076. [online] Available at: http://bg.sutr.ru/pdf. html?n=1480333788.pdf (access date: 09.12.2017). (In Russ.).

Tsonkhapa, Je (2007) Bol' shoe rukovodstvo k etapam puti probuzbdeniia : in 2 vol. St-Petersburg, A. Terentyev Publ. vol. 1. 786 p. (In Russ.).

Tsongkhapa, Je (2011) Bol'shoe rukovodstvo $k$ etapam puti mantry : in 2 vol. St-Petersburg, A. Terentyev Publ. vol. 1. 512 p. (In Russ.).

Shakabpa, V. D. (2003) Tibet: politicheskaia istoriia. St-Petersburg, "Nartang" Publ. 428 p. (In Russ.).

H. H. the Dalai Lama (2003) The Path to Enlightenment. Delhi, Motilal Banarsidass Publishers Pvt. Ltd. $238 \mathrm{p}$.

Thurman, Robert A.F. Life and Teachings of Tsongkbapa (2009). Dharamsala, Library of Tibetan Works \& Archives. 289 p.

rGyal-dbang chos-rje (2000) 'Jam-mgon chos-kyi rgyal-bo tsong-kba-ba chen-po' $i$ rnam-thar. Sarnath-Varanasi, XXIX GSWC CIHTS. 650 p. (In Tib.).

rJe tsongkhapa, blobzang gragspa (2001a) Lamgyi gtsobo rnampa gsumgyi rtsaba bzhugsso. In: Chosspyod rabgsal skalbzang skyebo' i mgulrgyan zhesbyaba zhugsso. Mundgod, Drepung Loseling Library Soceity. Pp. 344-347. (In Tib.).

rJe tsongkhapa, blobzang gragspa (2001b) Yontan gzhirgyurma bzhugsso. In: Chosspyod rabgsal skalbzang skyebo'i mgulrgyan zhesbyaba zhugsso. Mundgod, Drepung Loseling Library Soceity. Pp. 7-10. (In Tib.).

Tu'ubkvan, blobzang choskyi nyima (1984) Tu'ubkvan grubmtba'. Lanzhou, Kansu'u mirigs dpeskrunkhang. 487 p. (In Tib.).

Submission date: 19.12 .2017$.

Эрендженова Юлия Юрьевна - аспирант кафедры философии и культурологии Калмыцкого государственного университета им. Б. Б. Городовикова. Адрес: 358000, Россия, г. Элиста, ул. Пушкина, д. 11. Тел.: +7 (84722) 4-50-99. Эл. адрес: yulia.er16@gmail.com. Научный руководитель - А-р филос. наук, профессор К. А. Наднеева.

Erendzhenova Yulia Yurievna, Postgraduate Student, Department of Philosophy and Cultural Studies, Kalmyk State University named after B. B. Gorodovikov. Postal address: 11, Pushkina St., Elista, Russian Federation, 358000. Tel.: +7 (84722) 4-50-99. E-mail: yulia.er16@gmail.com. Scientific Adviser - K. A. Nadneyeva, Doctor of Philosophy, Professor. 